\title{
Editorial: Urban Futures
}

\author{
Karima Kourtit ${ }^{1,2}$ • Peter Nijkamp ${ }^{2,3}$. \\ Henk Scholten ${ }^{3}$
}

Received: 22 March 2015 / Accepted: 23 March 2015 /

Published online: 10 July 2015

(C) Springer Science+Business Media Dordrecht 2015

Our planet shows clear signs of an unprecedented population dynamics. Not only will the earth have to accommodate a few billion more people in the next decades to come, but also a rising share of the world population will move into urban agglomerations. A rough estimate of this population dynamic tells us that, on average, until the middle of this century, every week approximately 1 million people will become new urban dwellers (see Nijkamp and Kourtit 2013; UN-Habitat 2012).

This emerging mega-trend leads to new challenges for urban research and urban policy. Clearly, this accelerated urbanization trend is not the only trend faced by urban planners and policy makers; there are also other important - often interconnected challenges for cities, such as climate change, poverty and social stress, human health, accessibility and so forth. Consequently, urban systems tend to become complex entities with unexpected dynamics and phase transitions (Andersson and Andersson 2000). But these changes manifest themselves differently in different parts of the world. Urban mega-trends in Asia, Africa or Latin America are totally different from urban developments in Europe or North America. There is a clear need for a well-structured identification and analysis of multiple urban futures (Mega 2013; Randers 2011). In the

In Memoriam We would like to dedicate this special issue on 'Urban Futures' to the memory of Piet Rietveld, Professor of Transport Economics at the Vrije Universitiet (VU), who sadly passed away in 2014. Piet's academic contributions in the fields of transport and regional development, valuing the quality of transport services, public transport, land-use modelling and methods for policy analysis, were very substantial. It is a great privilege for us to be able to publish a paper written by Piet in this special issue of the journal, guest edited by his colleagues from the Department of Spatial Economics at the VU.

John Stillwell and Mark Birkin

Editors

\section{Karima Kourtit}

karima.kourtit@abe.kth.se

1 Department of Urban Planning and Environment, School of Architecture and Built Environment, KTH Royal Institute of Technology, Stockholm, Sweden

2 Faculty of Geography and Earth Sciences at Adam Mickiewicz University, Poznan, Poland

3 Department of Spatial Economics, VU University, Amsterdam, The Netherlands 
recent literature, we find various examples of such studies, sometimes focused on a given urban case study, sometimes focused on general patterns in a broad set of urban cases, and sometimes focused on specific features of cities (e.g., smart cities, digital cities). Likewise, some of these analyses are based on qualitative assessments, whereas other studies analyse quantitative urban data sets.

It should also be noted that increased urbanization does not necessarily mean that cities get bigger all the time (see Kourtit et al. 2014). There may also be a rise in new cities, while existing mono-centric cities may be transformed into poly-centric urban (or metropolitan) areas (like the Ruhr Area or the Dutch Randstad). A reliable and realistic mapping of different urban futures is, for the time being, not a plausible ambition, but an exploration of possible urban futures seems to be a more feasible research strategy.

This special issue of Applied Spatial Analysis and Policy seeks to offer a series of studies that focus the attention on drivers and features of the city of tomorrow. It does so by offering a multi-faceted menu for future studies on cities comprising: exploratory studies on urban mega-trends; ideal-types of cities based on stylized urban images which zoom in on a distinct important urban segment; and quantitative profile analysis of existing and future urban agglomerations.

We will now briefly summarize the various contributions in this special issue focusing on the future of urban systems. The first contribution, written by Ake Andersson and David Emanuel Andersson, offers a long-range mind map of creative cities as pivotal (physical and virtual) hubs in a globally connected world. Karima Kourtit, Peter Nijkamp and Mark Partridge then highlight a portfolio of research and policy challenges of the 'urban century', proposing the use of 'urban images' as core concepts for a better understanding of urban futures. One of such images, viz. the dramatic decline in transport and communication costs, is discussed by the late Piet Rietveld, who introduces the notion of 'flying carpet' for modern cities. Next, a second urban image, 'cyber cities', is introduced by Daniel Arribas-Bel, Karima Kourtit, Peter Nijkamp and John Steenbruggen; these authors focus attention in particular on the impact of social media use - in the form of urban buzz - in modern cities. A final image is presented by Raffaele Attardi, Fortuna De Rosa and Maria Di Palma, who introduce the 'bellissimo' image, seeking for a balance between protection of heritage and wealth creating initiatives.

The analysis of long-range tends in urban systems calls for novel research mythologies. Eveline van Leeuwen addresses the spatial imbalances between the urban and the rural world and identifies the backgrounds and strategies for creating spatial synergies. Finally, David Castells Quintana and Vincente Royuela investigate the fragile balance between the urbanizing world and emerging spatial inequalities.

In summary, this special issue of Applied Spatial Analysis and Policy contains a series of fascinating and original contributions on 'urban futures', written by various scholars. It is clear that the emerging 'century cities' prompts unprecedented research challenges for understanding and managing 'urban futures'. Strategic forward-looking on the 'New Urban World' is, therefore, a shared scholarly task for urban experts and policy makers.

\section{References}

Andersson, A. E., \& Andersson, D. E. (2000). Gateways to the global economy. Cheltenham: Edward Elgar. 
Kourtit, K., Nijkamp, P., Franklin, R. S., \& Rodríguez-Pose, A. (2014). A blueprint for strategic urban research: the urban piazza. Town Planning Review, 85(1), 97-126.

Mega, V. (2013). Forward cities in harmony with nature, people and. Regional Symbiosis, 21, 1-22.

Nijkamp, P., \& Kourtit, K. (2013). The 'New Urban Europe': global challenges and local responses in the urban century. European Planning Studies, 21(3), 291-315.

Randers, J. (2011). 2052 a global forecast for the next forty years. Vermont: Chelsea Green Publishing. UN-Habitat. (2012). State of the World's cities 2012/2013. Nairobi: UNHS Programme. 